\title{
Cecil Helman: GP, anthropologist, writer, poet, teacher, and internationalist
}

Cecil Helman, London GP and internationally renowned medical anthropologist and writer has sadly died, on 15 June 2009 at the Royal Free Hospital, from complications of motor neurone disease.

Cecil was born into a medical family in South Africa in 1944 and qualified at the University of Cape Town Medical School in 1967. He left South Africa soon after and came to Britain to take up general practice and study social anthropology at University College London under Professor Mary Douglas.

He continued to work for 27 years as a GP in North London but also pursued a parallel academic career in teaching and research as Senior Lecturer at University College and Professor at Brunel University. He was known internationally as one of the foremost experts in medical anthropology, the cross-cultural study of health, illness, and medical care. His seminal textbook, Culture, Health, and IIIness was first published in 1984. Now in its fifth edition it remains prominent on every GP trainee's reading list as well as those of other health professionals and students of anthropology. Not content to concentrate solely on clinical and academic pursuits he also became well known for his writing and poetry and was even known to turn his creative hand to painting.

Helman published academic papers in medical journals, including The Lancet, British Medical Journal, Annals of Internal Medicine, British Journal of General Practice, and Medical Humanities. He was honoured with several prestigious international prizes including, in 2008, the George Abercrombie Award made by the Royal College of General Practitioners for special meritorious literary work in general practice.

Perhaps Cecil Helman will be most remembered by the wider public for his recent memoir Suburban Shaman: Tales from Medicine's Frontline. This book received widespread critical acclaim, and was selected by the BBC as a 'Book of the Week', before being serialised on BBC Radio in March 2006. Any GP reading the book will recognise the many and varied doctor-patient interactions Cecil so eloquently describes from his own practice. The stories he tells are rich in context, challenging at times but so often amusing, powerful, and memorable. The resonance he communicates with day-to- day medical encounters can be shared by doctors and patients alike. It is a consolation to know that Cecil was working on his final book right up until the end. He submitted the manuscript for a sequel to Suburban Shaman provisionally entitled An Amazing Murmur of the Heart just days before his untimely death.

Cecil was a generous, supportive, and loyal friend to those around him. He remained always on good terms with his former wife Vetta, and was immensely proud of his daughter Zoe to whom he dedicated his many texts.

\section{Surinder Singh and Joe Rosenthal}

We shall be hosting a gathering in memory of $\mathrm{Dr}$ Cecil Helman at University College London (UCL) on the evening of 25 February 2010. For further details please contact: s.gerrard@pcps.ucl.ac.uk.

DOI: 10.3399/bjgp09X472782 